\title{
Docência em saúde: tempo de novas tecnologias da informação e comunicação
}

\author{
Health teaching: time of new information and communication \\ technologies
}

\section{Docencia en salud: tiempos de nuevas tecnologías de la información y comunicación}

Tatiana Peres Santana Porto Wanderley ${ }^{1, a}$

tatiporto3@gmail.com | https://orcid.org/o000-0002-2664-6585.

Mikael Henrique de Jesus Batista ${ }^{1, b}$

mikael.batista@ifto.edu.br | https://orcid.org/o0oo-0002-9277-8295

Lázaro da Silva Dutra Júnior ${ }^{1, c}$

lazarodutrajr@uol.com.br | https://orcid.org/oooo-00o1-6237-9739

Valdirene Cassia da Silva ${ }^{1, d}$

valdirene.silvao@gmail.com | https://orcid.org/o0oo-0002-1563-1222

${ }^{1}$ Universidade Federal do Tocantins. Palmas, TO, Brasil.

\footnotetext{
a Especialização em Educação na Saúde pelo Instituto Sírio Libanês de Ensino e Pesquisa.

b Especialização em Terapia Intensiva Geral e Urgência e Emergência pelo Centro Goiano de Ensino, Pesquisa e Pós-graduação.

'Especialização em Saúde Pública pela Universidade de Ribeirão Preto.

${ }^{d}$ Doutorado em Educação pela Universidade Federal da Bahia.
}

\section{Resumo}

Ao serem utilizadas no contexto educacional, as tecnologias digitais da informação e comunicação podem potencializar a aprendizagem, desenvolvendo ambientes de aprendizado, aprimorando e modernizando as práticas docentes. Nesta perspectiva, realizou-se um estudo com o objetivo de verificar a utilização dessas tecnologias como recurso didático-pedagógico em cursos da saúde. Os resultados evidenciaram as dificuldades citadas por docentes: estrutura escolar inadequada; formação acadêmica deficiente e resistência à utilização dessas tecnologias. Como estratégias para amenizar esses desafios foram enfatizadas a capacitação dos professores e a orientação para que conhecessem as especificidades dos recursos tecnológicos desde a sua formação. A plataforma Moodle, chat educacional e o fórum de discussão foram os mais utilizados. Concluímos que as instituições voltadas para o ensino da saúde não estão efetivamente utilizando as ferramentas com toda a sua potencialidade pedagógica e que, embora o acesso às tecnologias venha crescendo rapidamente, essa ampliação não é acompanhada de qualificação e transformação do processo de ensino.

Palavras-chave: Docentes; Comunicação; Tecnologias; Educação; Aprendizagem. 


\begin{abstract}
The digital technologies of information and communication, when used in the educational context, can potentialize learning developing learning environments, improving and modernizing teaching practices. From this perspective, a study was developed aiming to verify the use of these technologies as a didactic and pedagogical resource for courses in health. The results evidenced the difficulties mentioned by lecturers: inadequate universitary structure; deficient academic training and resistance to use these technologies. As strategies to soften these challenges, it was placed emphasis on the lecturer qualification and on the instruction in specificities of technological resources since their formation. The Moodle platform, the educational chat and the discussion forum were the most used. We conclude that the health education institutions are not effectively using all their pedagogical potential of the disposable tools and although access to the technologies is growing rapidly, this expansion is not followed by qualification and transformation of the teaching process.
\end{abstract}

Keywords: Lecturers; Comunication; Technologies; Education; Learning.

\title{
Resumen
}

Si las tecnologías digitales de la información y comunicación son utilizadas en el contexto educativo, pueden potenciar el aprendizaje, desarrollando ambientes de aprendizaje, perfeccionando y modernizando las prácticas docentes. En esta perspectiva se realizó un estudio con el objetivo de verificar la utilización de esas tecnologías como recurso didáctico y pedagógico en cursos de la salud. Los resultados evidenciaron las dificultades citadas por docentes: estructura escolar inadecuada; formación académica deficiente y resistencia a la utilización de esas tecnologías. Como estrategias para amenizar eses desafíos, el énfasis fue puesta en la capacitación de los profesores y en la orientación para que conozcan las especificidades de los recursos tecnológicos desde su formación profesionel. La plataforma Moodle, el chat educativo y el foro de discusión fueron los más utilizados. Concluimos que las instituciones de enseñanza de la salud no están efectivamente utilizando todo el potencial pedagógico de las herramientas disponibles y aunque el acceso a las tecnologías esté creciendo con rapidez, esa ampliación no es acompañada de la cualificación y transformación del proceso de enseñanza.

Palabras clave: Docentes; Comunicación; Tecnologías; Educación; Aprendizaje.

INFORMAÇÕES DO ARTIGO

\author{
Contribuição dos autores: \\ Concepção e desenho do estudo: Tatiana Peres Santana Porto Wanderley, Mikael Henrique de Jesus Batista, Lázaro da Silva \\ Dutra Júnior, Valdirene Cassia da Silva. \\ Aquisição, análise ou interpretação dos dados: Tatiana Peres Santana Porto Wanderley, Mikael Henrique de Jesus Batista, Lázaro da \\ Silva Dutra Júnior, Valdirene Cassia da Silva. \\ Redação do manuscrito: Tatiana Peres Santana Porto Wanderley. \\ Revisão crítica do conteúdo intelectual: Valdirene Cassia da Silva.
}

Declaração de conflito de interesses: Não há.

Fontes de financiamento: Não houve.

Considerações éticas: A pesquisa respeitou todos os preceitos éticos presentes em artigos de revisão bibliográfica, com a citação dos conhecimentos produzidos por outros autores, devidamente referenciada.

Agradecimentos/Contribuições adicionais: Agradecemos ao professor doutor José Lauro Martins, que no decorrer da disciplina Gestão do Aprendizado e Cibercultura do Programa do Mestrado Acadêmico Ensino em Ciência e Saúde, nos despertou quanto a relevância da temática abordada no presente artigo.

Histórico do artigo: Submetido: 19.abr.2018 | Aceito: 25.out.2018 | Publicado: 21.dez.2018

Apresentação anterior: Não houve.

Licença CC BY-NC atribuição não comercial. Com essa licença é permitido acessar, baixar (download), copiar, imprimir, compartilhar, reutilizar e distribuir os artigos, desde que para uso não comercial e com a citação da fonte, conferindo os devidos créditos de autoria e menção à Reciis. Nesses casos, nenhuma permissão é necessária por parte dos autores ou dos editores. 


\section{Introdução}

A abordagem tradicional das escolas e seu processo de ensino-aprendizagem resultam de uma concepção e práticas que perduram através do tempo e passaram a ser referencial para metodologias por meio das quais o professor é o centro do ensino e os alunos são ensinados e instruídos, por ele, em sala de aula, com valorização do conhecimento cumulativo'. Esse tipo de ensino é caracterizado por Mizukami como uma metodologia que preza a variedade e quantidade de conteúdo, e não a formação do pensamento reflexivo.

Em via oposta, encontramos propostas metodológicas de ensino centradas no aluno, de modo a criar condições para que o processo proporcione desenvolvimento cognitivo e emocional. Com o aluno envolvido como parte do processo, sentindo-se motivado em sala de aula, o aprender se torna mais interessante ${ }^{2}$. As tecnologias digitais usadas na educação podem potencializar as formas de comunicação, produção e disseminação das informações no processo ensino-aprendizagem ${ }^{3}$. Todavia, o mero uso de equipamentos digitais não constitui uma inovação metodológica. As tecnologias contemporâneas digitais, quando aplicadas à educação, a priori, são ferramentas de suporte e devem ser orientadas segundo os objetivos do processo educativo.

Atualmente, as tecnologias digitais de informação e comunicação (TDIC) fazem parte da nossa realidade nos mais diversos cenários; entretanto, sua utilização como instrumento no processo de ensinoaprendizagem, ainda encontra muitas barreiras: grande parte dos docentes apresenta resistência ao uso do método na educação, existe carência de atualização profissional nessa temática e a formação do professor não contempla a capacitação e o manuseio prático das diversas tecnologias existentes.

Nessa perspectiva torna-se importante entender como os professores estão trabalhando com as TDIC nos cursos da área da saúde, e com esse intuito realizamos um estudo com os objetivos de: verificar a utilização das tecnologias da educação e comunicação como recurso didático-pedagógico no processo de ensino-aprendizagem por parte dos docentes de cursos da saúde; identificar as principais dificuldades citadas para inserir as TDIC nesse processo; averiguar as recomendações para utilização dessa ferramenta na sua prática de ensino; e elucidar as ferramentas tecnológicas mais utilizadas.

\section{Metodologia}

Este estudo foi conduzido por meio de uma revisão narrativa da literatura, uma vez que essa abordagem apresenta uma temática mais ampla, isenta de um protocolo rígido para sua construção. Por ser menos abrangente, trata-se de uma estratégia metodológica adequada para a fundamentação teórica de artigos, dissertações, teses e trabalhos de conclusão de cursos. Nessa modalidade, a busca pelos materiais da literatura em questão não necessita esgotar as fontes de informações disponíveis e a seleção dos estudos e a interpretação das informações podem estar sujeitas à subjetividade dos autores ${ }^{4,5}$.

Os estudos foram coletados por meio do Portal de Periódicos Capes e da Biblioteca Virtual em Saúde. A coleta foi realizada com a utilização dos seguintes descritores: docentes; comunicação; tecnologias. Foram encontradas 1.599 publicações nas bases de dados pesquisadas e, ao serem aplicados os critérios de inclusão e exclusão, obteve-se uma amostra de 19 artigos, dos quais 12 se encontram no Portal de Periódicos da Capes/MEC e sete na Biblioteca Virtual em Saúde.

A pesquisa ocorreu entre os meses de dezembro de 2017 e março de 2018, incluindo a coleta de dados e a análise a partir de materiais científicos relacionados ao tema selecionados.

Foram considerados como critérios de seleção da população do estudo: a) período de 2008 até 2018; b) conteúdo relacionado à docência na área da saúde e uso das TCIS; c) idioma português; espanhol; inglês; d) disponibilização do artigo na íntegra. Foram excluídos textos repetidos e aqueles que não contemplavam nenhum dos objetivos da pesquisa (Figura 1). 
Docência em saúde: tempos de tecnologias da informação e comunicação

Descritores: Docentes; Comunicação; Tecnologias.

Portal de periódicos CAPES: 1539 publicações;

Biblioteca Virtual em Saúde: 60 publicações

Portal Capes: 1539 publicações

Exclusão:

- Fora do período estabelecido entre 2008 e 2018: 107 publicações;

- Não traziam o texto na integra: 20 publicações;

-Textos repetidos: 35 publicações;

- Não contemplaram os objetivos: 1364 publicações;

- Amostra: 12 publicações.
Biblioteca virtual em Saúde: 60 Publicações

Exclusão:

- Fora do período estabelecido entre 2008 e 2018: 13 publicações;

- Não traziam o texto na integra: 3 publicações;

-Textos repetidos: 10 publicações;

- Não contemplaram os objetivos: 27 publicações;

- Amostra: 7 publicações.

\section{Amostra final: 19}

Figura 1 - Desenho do estudo, critérios de inclusão e exclusão, amostra final Fonte: Os autores (2018).

Para examinar o material pesquisado, primeiro foi realizada uma leitura criteriosa dos textos e, em seguida, houve a análise do conteúdo de cada um deles de forma que permitisse identificar a docência na área da saúde e uso das TDCI.

Os dados foram compilados e analisados à luz da literatura pertinente e são apresentados de forma descritiva, tabular e gráfica.

\section{Resultados}

Nos processos educacionais mediados pelas TDIC cabe ao docente organizar e orientar uma aprendizagem com autonomia e proatividade do discente, mobilizando os diversos saberes, atuando em equipe, estabelecendo a criatividade e aprendendo ao mesmo tempo que ensina ${ }^{6}$. No entanto, para a inserção das TDIC, antes de reestruturar/informatizar escolas e capacitar docentes para manuseá-las, necessitamos de um novo método pedagógico, um ensino que promova a criticidade e novas habilidades cognitivas do aluno7 ${ }^{7}$ Dentro desse contexto, após gerenciar os dados coletados na presente pesquisa, foi possível elaborar o quadro a seguir, com a finalidade de manter uma visão holística acerca dos achados. 
Quadro 1 - Estudos (ordem cronológica) sobre utilização, pelos docentes, de tecnologias da educação e comunicação como recurso didático-pedagógico em cursos da área da saúde 2008-2018

\begin{tabular}{|c|c|c|c|}
\hline Autor & Título & Periódico & Ano \\
\hline Arco $A R^{8}$ & $\begin{array}{l}\text { Tecnologias da informação e da comunicação na } \\
\text { educação em saúde. O caso da formação em } \\
\text { enfermagem }\end{array}$ & $\begin{array}{l}\text { Relatec- Revista } \\
\text { Latino-americana de } \\
\text { Tecnologia Educativa }\end{array}$ & 2009 \\
\hline Santos $\mathrm{GL}^{9}$ & $\begin{array}{l}\text { Ensinar e aprender no meio virtual: rompendo } \\
\text { paradigmas }\end{array}$ & Educação e Pesquisa & 2011 \\
\hline $\begin{array}{l}\text { Silva ISA } \\
\text { Marques } \mathrm{IR}^{10}\end{array}$ & $\begin{array}{l}\text { Conhecimento e barreiras na utilização dos recursos da } \\
\text { tecnologia da informação e comunicação por docentes } \\
\text { de enfermagem }\end{array}$ & $\begin{array}{l}\text { Journal of Health } \\
\text { Informatics }\end{array}$ & 2011 \\
\hline Francisco $\mathrm{CCB}^{11}$ & $\begin{array}{l}\text { Formação docente: o uso de conteúdos midiáticos e } \\
\text { das TIC no processo de ensino e de aprendizagem no } \\
\text { ensino superior }\end{array}$ & $\begin{array}{l}\text { Acta Scientiarum } \\
\text { Education }\end{array}$ & 2011 \\
\hline $\begin{array}{l}\text { Soares-Leite WS } \\
\text { Nascimento-Ribeiro } \\
\text { CA }^{12}\end{array}$ & $\begin{array}{l}\text { A inclusão das TIC na educação brasileira: problemas e } \\
\text { desafios }\end{array}$ & $\begin{array}{l}\text { Magis, Revista } \\
\text { Internacional de } \\
\text { Investigación en } \\
\text { Educación, }\end{array}$ & 2012 \\
\hline Peres CM et al. ${ }^{13}$ & $\begin{array}{l}\text { Aprendizado eletrônico na formação multiprofissional } \\
\text { em saúde: avaliação inicial }\end{array}$ & \begin{tabular}{|l|} 
Revista Brasileira de \\
Educação Médica \\
\end{tabular} & 2012 \\
\hline Quiroz JES ${ }^{14}$ & $\begin{array}{l}\text { Estándares TIC para la formación inicial docente: una } \\
\text { política pública en el contexto chileno }\end{array}$ & $\begin{array}{l}\text { Archivos analíticos de } \\
\text { políticas educativas }\end{array}$ & 2012 \\
\hline $\begin{array}{l}\text { Goudouris ES } \\
\text { Giannella TR } \\
\text { Struchiner } \mathrm{M}^{15}\end{array}$ & $\begin{array}{l}\text { Tecnologias de informação e comunicação e ensino } \\
\text { semipresencial na educação médica }\end{array}$ & $\begin{array}{l}\text { Revista Brasileira de } \\
\text { Educação Médica }\end{array}$ & 2013 \\
\hline Leite KNS ${ }^{16}$ & $\begin{array}{l}\text { A utilização das tecnologias da informação e } \\
\text { comunicação pelos docentes de enfermagem e as } \\
\text { dificuldades no processo de ensino-aprendizagem }\end{array}$ & $\begin{array}{l}\text { Dissertação de mestrado } \\
\text { (UFPB) }\end{array}$ & 2014 \\
\hline $\begin{array}{l}\text { Rodrigues SC } \\
\text { Morales } \mathrm{LS}^{17}\end{array}$ & A lousa digital na ação docente & Prisma.com & 2015 \\
\hline $\begin{array}{l}\text { Muñoz Vargas IC } \\
\text { Monroy Íñiguez FJ } \\
\text { Pichardo CMR }{ }^{18}\end{array}$ & $\begin{array}{l}\text { Desarrollo de competencias integrales con tecnologías } \\
\text { de la información y de la comunicación en educación } \\
\text { superior a distancia. }\end{array}$ & Panorama & 2015 \\
\hline Bueno DA ${ }^{19}$ & Comunicação, mídia e cidadania na prática pedagógica & Inter-Ação & 2015 \\
\hline Santos $A^{20}$ & $\begin{array}{l}\text { Tecnologias de informação e comunicação: limites e } \\
\text { possibilidades no ensino superior }\end{array}$ & $\begin{array}{l}\text { Rebes - Revista Brasileira } \\
\text { de Ensino Superior }\end{array}$ & 2015 \\
\hline $\begin{array}{l}\text { Tinjacá JAW } \\
\text { García LLA } \\
\text { Sierra HFG }{ }^{21}\end{array}$ & $\begin{array}{l}\text { De los viejos individualismos a las nuevas sociedades: } \\
\text { tecnologías de la información en la cualificación de } \\
\text { prácticas docentes universitarias }\end{array}$ & $\begin{array}{l}\text { Revista Lassalista de } \\
\text { investigacíon }\end{array}$ & 2016 \\
\hline Leite KNS et al. ${ }^{22}$ & $\begin{array}{l}\text { Uso da tecnologia da informação e comunicação entre } \\
\text { docentes à luz da teoria fundamentada nos dados }\end{array}$ & $\begin{array}{l}\text { Revista enfermagem } \\
\text { UFPE online }\end{array}$ & 2016 \\
\hline $\begin{array}{l}\text { Beltrán, NMR et } \\
\text { al. }{ }^{23}\end{array}$ & $\begin{array}{l}\text { Clínica virtual docente: un espacio formativo para la } \\
\text { enseñanza de las ciencias médicas }\end{array}$ & Revista Medisan & 2017 \\
\hline $\begin{array}{l}\text { Cerutti E } \\
\text { Nogaro } A^{24}\end{array}$ & $\begin{array}{l}\text { Desafios docentes no ensino superior: entre a } \\
\text { intencionalidade pedagógica e a inserção da tecnologia }\end{array}$ & $\begin{array}{l}\text { RIAEE- Revista Ibero- } \\
\text { Americana de Estudos } \\
\text { em Educação }\end{array}$ & 2017 \\
\hline Cunha NC et al. ${ }^{25}$ & $\begin{array}{l}\text { Gestão do conhecimento nas relações da sociedade da } \\
\text { informação pela web }\end{array}$ & Revista Sustinere & 2017 \\
\hline $\begin{array}{l}\text { Heredia JM } \\
\text { Moraes M } \\
\text { Vieira EMF26 }\end{array}$ & $\begin{array}{l}\text { Uso de tecnologias digitais de informação e } \\
\text { comunicação por docentes }\end{array}$ & Revista Conexão UEPG & 2017 \\
\hline
\end{tabular}

Fonte: Os autores (2018). 
Antes de iniciar as discussões e análise dos dados, apresentamos a seguir os resultados da pesquisa em forma tabular e gráfica.

Tabela 1 - Principais dificuldades citadas pelos docentes da saúde para utilização das tecnologias da educação e comunicação como recurso didático-pedagógico

\begin{tabular}{ll} 
Dificuldades citadas & $\mathbf{n}$ \\
\hline Formação acadêmica deficiente na inclusão das novas tecnologias & 06 \\
Estrutura escolar inadequada & 06 \\
Resistência de professores às novas tecnologias & 06 \\
Falta investimento financeiro & 04 \\
Formação continuada para professores inexistente & 05 \\
Currículos escolares tradicionais & 03 \\
Falta de tempo para preparar as TIC & 03 \\
Dificuldade de avaliar a aprendizagem por meio das tecnologias & 01 \\
Acesso limitado às tecnologias & 03 \\
Ausência de políticas pedagógicas & 01 \\
\hline Total & $\mathbf{3 8}$
\end{tabular}

Fonte: Os autores (2018).

A tabela 1 ilustra as principais dificuldades citadas pelos docentes da saúde para utilização das tecnologias da educação e comunicação como recurso didático-pedagógico, considerando que houve artigos que citaram mais de uma dificuldade, fato que justifica o total de 38 citações.

De acordo com a pesquisa realizada, onde notamos a prevalência de estrutura escolar inadequada com $\mathrm{n}=6$, formação acadêmica deficiente dos docentes quanto à inclusão das novas tecnologias; resistência de professores à utilização das mesmas também com $\mathrm{n}=6$ e investimento financeiro insuficiente, citado por $\mathrm{n}=4$. Notamos ainda a inexistência da formação continuada para os docentes e os currículos escolares tradicionais, que foram citados por $\mathrm{n}=5$ e $\mathrm{n}=3$ da amostra, respectivamente.

Tabela 2 - Recomendações aos docentes para utilização eficaz das tecnologias da educação e comunicação como recurso didático-pedagógico

(Continua)

\begin{tabular}{lc}
\hline Recomendações & n \\
\hline Conhecer as especificidades dos recursos tecnológicos desde a formação & 06 \\
Capacitação dos professores & 09 \\
Acesso à infraestrutura tecnológica & 06 \\
Inserir o uso das tecnologias no planejamento da aula & 04 \\
Letramento digital de docentes e alunos & 04 \\
Repensar sua prática pedagógica & 03
\end{tabular}


(Conclusão)

\begin{tabular}{ll}
\hline Recomendações & $\mathbf{n}$ \\
\hline Professor deve ser o facilitador da aprendizagem & 02 \\
Equipe de suporte técnico para o docente & 03 \\
Romper o ensino transmissivo & 02 \\
Pesquisas sobre a temática & 02 \\
Mobilização de toda comunidade escolar & 02 \\
Autoria do aluno na aprendizagem & 01 \\
Gestão ser agente motivador & 02 \\
Abertura da escola ao exterior (comunidade) & 01 \\
Desenvolvimento de materiais didáticos para a sala de aula virtual & 01 \\
Flexibilidade curricular & 01 \\
\hline Total & 49 \\
\hline
\end{tabular}

Fonte: Os autores (2018).

Temos na tabela 2 o demonstrativo das recomendações aos docentes para utilização eficaz das tecnologias da educação e comunicação como recurso didático-pedagógico, conforme autores pesquisados, onde obtivemos que a recomendação mais citada foi a capacitação dos professores com $\mathrm{n}=9$, seguida da orientação para que os professores conheçam as especificidades dos recursos tecnológicos desde a sua formação, feita por $n=6$ dos autores. $O$ acesso à infraestrutura tecnológica foi citado por $n=6$, a inserção do uso das tecnologias no planejamento da aula e o letramento digital de docentes e alunos, foram citados por $\mathrm{n}=4$ dos autores. Justifica-se o total de 49 na tabela 2, em detrimento da amostra ser composta por 19 referências, pelo fato de um mesmo autor ter citado mais de uma recomendação.

O gráfico 1 abaixo ilustrado demonstra as ferramentas tecnológicas mais utilizadas pelos docentes da saúde como recurso didático-pedagógico. Segundo o estudo realizado, percebemos a prevalência da educação a distância (EAD); chat educacional e plataforma moodle, citados por $n=6$ dos autores, seguidos pelo fórum de discussão que foi referido por $\mathrm{n}=5$ das referências da amostra. 
Gráfico 1 - Ferramentas tecnológicas mais utilizadas pelos docentes da saúde como recurso didático pedagógico

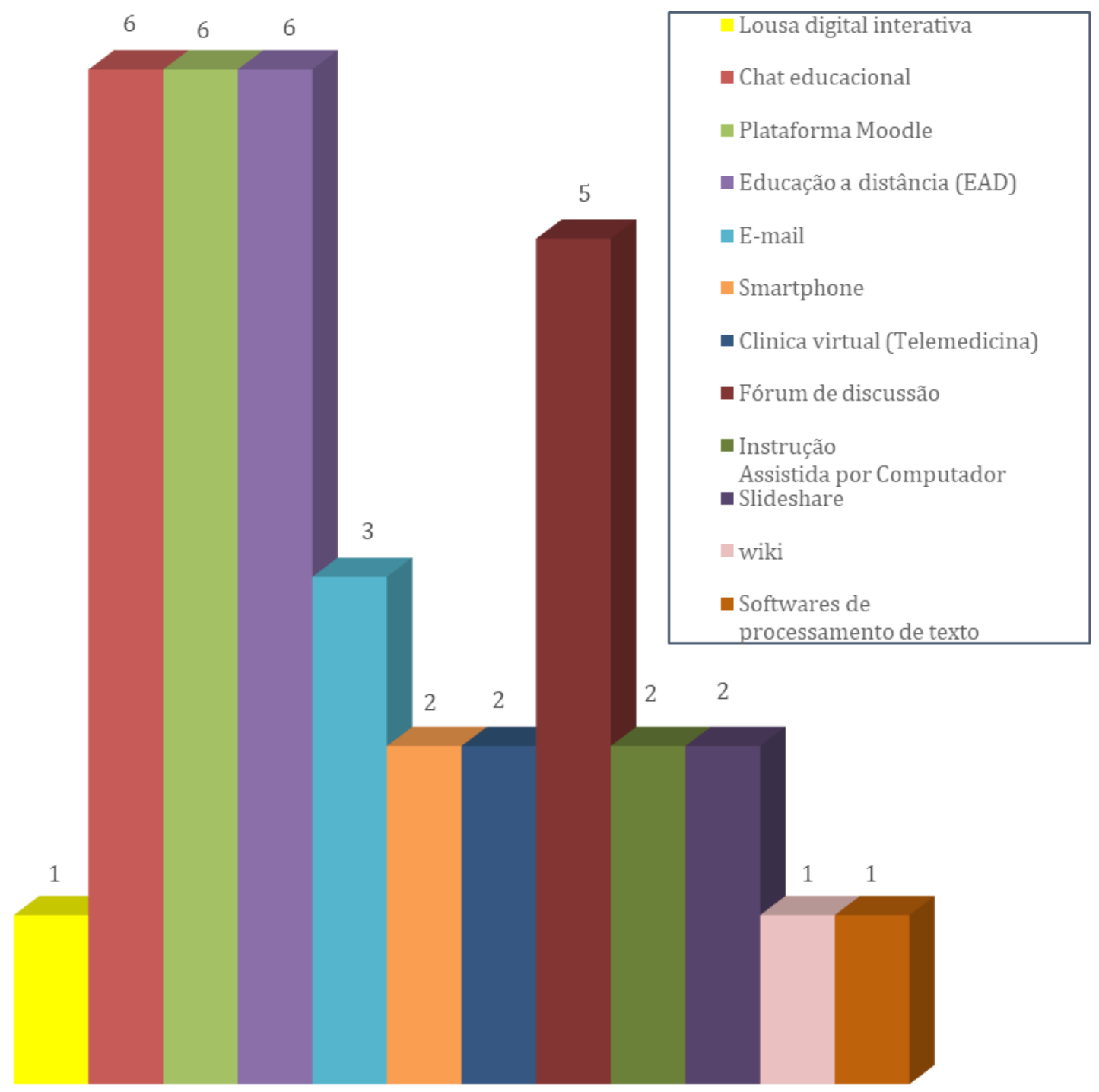

Fonte: Os autores (2018)

\section{Discussões}

Ao serem utilizadas no contexto educacional, as tecnologias digitais da informação e comunicação (TDIC) podem potencializar a aprendizagem dos discentes, desenvolvendo ambientes de aprendizagem, aprimorando e modernizando as práticas docentes, entre outros ${ }^{20}$. Atualmente estamos em frente de uma geração de aprendizes habituada desde o nascimento com a utilização de computadores, smartphones, redes sociais e pesquisas através da internet, e nesse contexto a aprendizagem baseada em simplesmente transmitir o conteúdo é insipiente ${ }^{26}$.

As TDIC facilitam o acesso, a comunicação e possibilitam a manipulação de diversas fontes de informação $0^{6}$. Entretanto, a sua incorporação na educação têm sido um desafio para grande parte dos docentes, visto que, deve haver uma prática pedagógica, alinhada às expectativas e às necessidades de ensino e aprendizagem, que contemple as competências previstas nos projetos pedagógicos. Os docentes além de apoiar a busca de informações, devem acima de tudo, orientar os aprendentes a filtrarem os conteúdos, analisá-los criticamente e construírem o próprio conhecimento ${ }^{26}$.

Ao analisar a tabela 1, percebemos que os resultados obtidos revelam que os autores dessa literatura estão em consonância sobre os principais obstáculos que os docentes encontram para incorporar as TDIC 
na educação, ou seja: tempo escasso para preparar a metodologia; acesso reduzido às ferramentas; custo elevado de equipamentos; capacitação ineficiente; e dificuldade para avaliar formalmente o aprendizado possibilitado pelas tecnologias. Os professores necessitam receber treinamento na temática no período de sua formação, o qual deverá ter continuidade durante todo o exercício da profissão ${ }^{14}$.

Em um estudo realizado com docentes do curso de enfermagem sobre as dificuldades de utilização das TDIC, os resultados evidenciaram com destaque: falta de investimento financeiro, bem como de políticas pedagógicas na instituição; ausência de capacitação docente e de preparo dos estudantes, corroborando os achados da presente pesquisa ${ }^{22}$. Outra pesquisa com docentes do mesmo curso, trouxe que os mesmos utilizam as TDIC em algumas das atividades da docência, têm acesso a muitos recursos, mas desconhecem várias outras ferramentas. Para eles, um maior investimento da instituição em tecnologias, impulsionaria a adoção das mesmas; acreditam não só estar aptos a usar as TDIC como no potencial que elas têm de melhoria do método. Os resultados, entretanto, também mostraram que a maioria dos docentes domina apenas os recursos básicos, insuficientes para novas práticas pedagógicas utilizando esses recursos ${ }^{10}$.

A questão não é mais discutir a inserção ou não das TIC na educação, mas sua apropriação, pelos alunos e professores, para melhorar a qualidade dos processos educativos e da aprendizagem. Os aprendentes, apesar de serem considerados 'nativos digitais', são consumidores compulsivos de inúmeras tecnologias e mídias que frequentemente não percebem que as mesmas são recursos de aprendizagem. $\mathrm{O}$ fato acontece ainda com os docentes que, apesar de utilizarem as tecnologias, não as reconhecem como recurso didático e até mesmo as rejeitam para uso no ensino. É importante reconhecer que os meios de comunicação já têm realizado uma função educativa, embora desvinculada dos sistemas oficiais de ensino ${ }^{19}$.

A resistência demonstrada por alguns docentes tem como principal causa a falta de preparo e familiaridade com o uso das tecnologias, além de se referirem que, na área da saúde, existe a crença de que o ensino virtual não é adequado, pois existe uma obrigatoriedade do contato do aluno com o ser humano ${ }^{22}$. A insuficiência dos programas de capacitação e atualização dos docentes também mereceu destaque entre os fatores dificultadores. Uma capacitação periódica no uso de tecnologias, dentro da carga horária do professor, seria uma forma de transformar o ensino, proporcionando uma aprendizagem mais crítica e menos bancária, em que o docente atua como auxiliar na construção do conhecimento do aprendente. Entretanto, alguns professores citam que, nas universidades, persistem a falta de segurança na transmissão de dados e uma dificuldade para selecionar os conteúdos a serem trabalhados com os estudantes ${ }^{22}$.

Os centros formadores necessitam desenvolver estratégias para que os docentes e alunos façam ampla utilização de equipamentos, softwares, entre outros. Porém, não é o suficiente, faz-se imprescindível uma reestruturação do sistema educacional, incluindo as políticas organizacionais, a gestão e as formas de avaliação $0^{6}$. Desenvolver uma nova forma de avaliar é um dos maiores desafios, visto que a própria legislação brasileira sobre educação a distância diz que as avaliações nessa modalidade, para serem válidas, devem ser presenciais. Nesse contexto é provável que os docentes não tenham ainda adquirido a confiança em um sistema de avaliação informatizado, seja formativo ou não ${ }^{15}$.

O docente que trabalha pautado por diálogo, flexibilidade, interação e motivação dos aprendentes será bem-sucedido em qualquer ambiente educativo. Porém, o professor que usa metodologias tradicionais ancoradas nas aulas expositivas dificulta o diálogo com os alunos e consequentemente reproduzirá a falha de comunicação do meio tradicional, também em qualquer outro cenário de aprendizagem. Nos ambientes virtuais, o docente precisa desempenhar o papel de motivador e orientador do processo de estudos, levando o aluno à realização dos objetivos de aprendizagem, mantendo-o em atividade e evitando a dispersão9.

Em uma pesquisa com docentes sobre o uso de tecnologias digitais, concluiu-se que há necessidade de promover formação continuada para transformação dos processos educacionais e notou-se ainda que a carga horária docente não permitia tempo disponível para participação em capacitações e atualizações ${ }^{26}$. Um estudo sobre desenvolvimento de competências docentes no uso das tecnologias no ensino a distância 
elucidou que o nível de habilidade tecnológica dos docentes estava abaixo do esperado, que os docentes não compreendem ao certo o conceito de 'estratégia didática' e tampouco têm conhecimento da diversidade de ambientes mediados por TIC na educação $0^{18}$.

Entre as recomendações aos docentes para utilização eficaz das tecnologias da educação e comunicação como recurso didático-pedagógico, demonstradas na tabela 2, inferiu-se que os discentes não possuem habilidades para fazer o uso pedagógico das tecnologias, cabendo ao professor ser o mediador desse processo. Ao docente não basta apenas saber manusear essas ferramentas, faz-se necessário conhecimento para integrá-las nos currículos das disciplinas como peças importantes do ensino e aprendizagem. Além disso, deve estar capacitado em métodos de avaliação adequados para a nova pedagogia e recursos mais indicados para cada cenário de ensino ${ }^{14}$.

Estudos têm demonstrado a necessidade de que as instituições de ensino invistam na capacitação tecnológica docente e discente. Desenvolver projetos pedagógicos que contemplem o ensino virtual e a incorporação das TDIC na educação também se torna imprescindível para a construção de competências dos aprendentes ${ }^{22}$. Em concordância com o exposto foi citado na literatura que para a inclusão das TIC o maior desafio é a mudança do denominado ensino tradicional, para um ensino voltado a novas metodologias de ensino, que valorize o conhecimento prévio do aluno, além da superação da resistência de alguns professores ao novo e falta de capacitação quanto ao uso das tecnologias ${ }^{20}$.

A inclusão bem-sucedida das tecnologias na educação é multifatorial, destacando-se: uma boa formação docente que contemple domínio das principais tecnologias, bem como da sua utilização na prática; estrutura física e material adequado nas escolas; investimentos governamentais em atualizações constantes para os professores; interesse dos docentes na inovação das suas aulas e currículos escolares que favoreçam a utilização das TDIC nas diversas disciplinas ${ }^{12}$.

Quanto à formação dos professores, não significa apenas formar profissionais aptos a operar as ferramentas tecnológicas e atender às exigências do mercado de trabalho, implica em capacitar indivíduos para perceber, questionar, manusear e criar tecnologias. O docente deve ser capaz de formar pessoas autônomas e competentes na tomada de decisões para a vida social e profissional ${ }^{6}$.

As tecnologias digitais trouxeram a necessidade de constituir novas relações de trabalho e de ensino, bem como modificaram a relação entre professores e alunos; com elas, emergiram outras possibilidades de aprendizagem, compartilhamento de informações e conteúdo. Nesse cenário, o docente deve legitimar o seu ensino, motivando o aluno, controlando a dispersão, a desistência e, ao mesmo tempo, mantendo a qualidade do seu ofício. O professor necessita elaborar um modelo de aula em que as tecnologias sejam inseridas, mas, com componentes de valorização social, ética, afetiva e emocional da sua profissão de educador ${ }^{25}$.

É importante que, ao iniciar o processo de ensino-aprendizagem, o docente avalie o conhecimento prévio dos alunos acerca das TDIC, além de se inteirarem do que consomem nas mídias e do contexto em que estão inseridos, para que assim possa planejar atividades direcionadas ao atendimento das necessidades individuais ${ }^{11}$. Assim, o professor deve ser um orientador, ou seja, alguém que não domina todo o conhecimento existente, mas que mostra aos discentes como aprender, buscar, classificar e selecionar a informação relevante ${ }^{20}$.

Notamos que não há uma fórmula pronta de inserção das TDIC; uma estratégia recomendada é estabelecer uma comunicação eficaz com os alunos, levando em consideração o conhecimento prévio dos mesmos e estabelecendo uma aprendizagem colaborativa ${ }^{11}$. Alguns autores recomendam a construção de um guia didático metodológico para docentes com estratégias estabelecidas e que haja a divulgação desse material junto aos comitês curriculares de cada programa. Sugerem, ainda, o desenvolvimento de materiais educacionais a fim de gerar dinâmica de trabalho e treinamento adequado para os professores em questão a fim de se tornarem multiplicadores das TDIC ${ }^{18}$. 
O processo de formação docente deve permitir o desenvolvimento progressivo e sustentado de competências técnico e práticas com análise dos recursos materiais e equipamentos. Os gestores necessitam ser motivadores, além de exercerem o papel normativo e regulador de escolha dos materiais para uma aplicação criativa, interativa e dinâmica das tecnologias em sala de aula e outros cenários de ensinoaprendizagem ${ }^{8}$. Cabe ressaltar que as TDIC podem ser utilizadas para implementar modelos e processos educativos integradores, mas sozinhas não garantem a resolução de todas as demandas e problemas da formação dos profissionais da saúde. O sucesso depende da visão de educação, de tecnologia e de saúde dos profissionais que as adotam, no caso, os docentes, sendo imprescindível disponibilizar aos professores tecnologias fáceis de serem compreendidas e utilizadas, além de apoio tecnológico e pedagógico ${ }^{15}$.

Entre as ferramentas tecnológicas mais utilizadas pelos docentes da saúde como recurso didáticopedagógico, a EAD é uma modalidade educacional em que a orientação didático-pedagógica no ensino se dá através de recursos das tecnologias de informação e comunicação, e as atividades educativas acontecem em lugares e momentos diversos. O Ministério da Educação e Cultura (MEC) regulamenta que os programas de EAD podem possuir distintos formatos e combinações de linguagens, de acordo com o curso a ser oferecido, as condições cotidianas e as necessidades dos discentes.

A metodologia, os encontros presenciais, estágios supervisionados, práticas laboratoriais, tutoriais serão definidos nesse contexto. Cabe ressaltar que, apesar de contemplar variadas formas de organização, todos os cursos de EAD devem refletir e compreender a educação como fundamento primordial, o verdadeiro sentido de educar, para somente então definire a estruturação de uma modalidade à distância ${ }^{20}$.

Entretanto, pesquisas realizadas em cursos distintos da área de ciências biomédicas evidenciaram que os ambientes de ensino a distância são, na maior parte das vezes, utilizados para oferecer informações sobre cursos, textos e outros materiais meramente informativos. Isso reforça a notória tendência de os professores utilizarem recursos de comunicação em cursos online apenas para troca de informações administrativas e pontuais em detrimento de estabelecer relação dialógica e colaborativa no processo de aprendizagem ${ }^{15}$.

As pesquisas também evidenciaram que o Moodle foi o instrumento mais utilizado por docentes do curso de enfermagem, sendo considerada uma estratégia eficaz para modificar o ensino-aprendizagem, visto que permite momentos de aprendizagem coletiva e individual, interação, questionamentos ou interpretação de textos orientados pelo docente ${ }^{22}$.

Alguns estudos evidenciaram que, em geral, os docentes utilizam os mesmos tipos de recursos e não há um tratamento pedagógico adequado, fato que influencia negativamente os processos de comunicação. Em parte, esses aspectos são atribuídos à falta de treinamento e capacitação desses professores. Já os aprendentes revelaram dificuldades com a estratégia didática proposta nas atividades da plataforma Moodle, citando que não ficam totalmente esclarecidas as técnicas, prejudicando o entendimento e o desenvolvimento de questionamentos. Tal resultado demonstra a necessidade da capacitação do docente para elaborar uma estratégia didática clara e precisa de modo a trabalhar harmoniosamente os conteúdos ${ }^{18}$.

Uma dissertação de mestrado evidenciou que os docentes utilizam as tecnologias da informação e comunicação, mas alguns com menor frequência, por insegurança, sendo as mais utilizadas: o e-mail, por todos, e a plataforma Moodle apenas por alguns. A autora levantou que alguns professores consideram que o ensino da enfermagem deve ser exclusivamente presencial e os ambientes virtuais de aprendizagem são dispensáveis ${ }^{16}$.

A Clínica Virtual é um espaço de ensino, contendo casos clínicos das várias especialidades, e nessa modalidade encontramos: estudo de caso; discussão de diagnóstico e de problemas de saúde. Contempla ainda um serviço de perguntas aos especialistas e consulta clínica da segunda opinião, para fins educacionais, bem como uma galeria de imagens por especialidades ${ }^{23}$. O Wiki, uma plataforma que possibilita a edição conjunta de documentos em ambientes de desenvolvimento colaborativo na internet, tem sido utilizado nas relações pedagógicas em sala de aula virtual ${ }^{9}$. Ambos não foram citados em muitos estudos. 
O fato é que os alunos conhecem e utilizam as tecnologias, independentemente do docente apoiar ou não a ferramenta usada. O desafio é integrar essa metodologia ao ensino, de forma que os aprendentes passem a usá-las de modo responsável, didático e construtivo. Recomenda-se que, ao utilizarem as tecnologias, os professores e alunos trabalhem juntos, até mesmo criando espaços virtuais de aprendizagem, em parceria, unindo seus conhecimentos. Inserir novas tecnologias na educação significa estar em sintonia com o discurso dos estudantes, entender sua linguagem e expressões, fazê-los sentir que 'vivemos' no mesmo mundo. As pesquisas sobre a temática e as iniciativas dos docentes são um primeiro passo nesse caminho ${ }^{21}$.

\section{Considerações finais}

Ao concluir este estudo, percebemos que as Instituições de Ensino Superior (IES) que atuam nos cursos da área de saúde não estão efetivamente utilizando as TDIC com toda a sua potencialidade pedagógica na educação, em grande parte devido à falta de preparo e capacitação dos docentes, mas sem esquecer a importância da parte institucional nesse processo, que inclui disponibilizar recursos básicos, como acesso à internet, notebook, data show, tela multimídia, entre outros. Ressaltamos ainda que possuir uma excelente estrutura tecnológica não é o suficiente para garantir a inserção das tecnologias nos processos de ensino-aprendizagem. Embora, o acesso às tecnologias venha crescendo rapidamente, essa ampliação não é acompanhada de qualificação e transformação do processo de ensino.

Notadamente, a adoção das tecnologias no contexto educacional demanda processos de acomodação e adaptações dos docentes e aprendentes, quando se trata dos cursos de saúde, o mercado de trabalho já necessita e exige um profissional qualificado e habituado ao uso das várias ferramentas tecnológicas, considerando que vivemos um momento de informatização de clínicas, hospitais, com prontuários eletrônicos e equipamentos. Quanto mais o profissional em formação utilizar as TIC antes de adentrar no mercado de trabalho, mais facilmente ele se habituará a usá-las no atendimento ao seu paciente.

Para os docentes, uma das estratégias a ser utilizada é a formação continuada, mas é preciso querer mudar, aprender e adaptar; o professor deve ter um papel ativo junto às instituições na integração das TIC aos currículos. Consideramos que as instituições necessitam promover discussões e ações para implantação dos novos recursos metodológicos no ensino, visto que no mundo digital em que estamos inseridos, a docência exige mais que dominar um conteúdo, é preciso um conjunto de competências teóricas, pedagógicas e habilidades, ao menos básicas, no uso das TDIC.

Trabalhar de forma eficaz com as tecnologias exige novos modelos de aprendizagem que contemplem as ferramentas tecnológicas. O docente é o mediador entre o aluno e o conhecimento, e o sistema educacional necessita vencer o abismo existente entre os aprendentes munidos com dispositivos eletrônicos e digitais e escolas com seus currículos tradicionais, métodos e linguagem analógicos.

\section{Referências}

1. Mizukami MGN. Ensino: As abordagens do processo. São Paulo: EPU; 1986.

2. Brait LFR, Macedo KMF, Silva FB, Sila FB, Souza ALR. A relação professor/aluno no processo de ensino e aprendizagem. Itinerarius Reflectionis [Internet]. 2010 [citado em 2018 nov 21];8(1):1-15. Disponível em: https://www.revistas.ufg.br/rir/article/view/40868

3. Kenski VM. Educação e tecnologias: o novo ritmo da informação. Campinas: Papirus; 2007.

4. Cordeiro AM, Oliveira GM, Rentería JM, Guimarães CA. Revisão sistemática: uma revisão narrativa. Rev Col Bras Cir [Internet]. 2007 [citado em 2018 nov 21];34(6):428-31. doi: http://dx.doi.org/10.1590/ S0100-69912007000600012 
5. Ferenhof HA, Fernandes RF. Desmistificando a revisão de literatura como base para redação científica: Método Ssf. Rev ACB [Internet].2016 [citado em 2018 nov 21];21(3):550-63. Disponível em: https:// revista.acbsc.org.br/racb/article/download/1194/pdf

6. Martins JL. Enquanto uns ensinam, outros navegam: a gestão da aprendizagem em tempos digitais. Porto Alegre: Fi; 2017.

7. Gilberto IJL. As tecnologias digitais na fronteira do conhecimento: a inter-relação educação cultura no ensino superior. Inter-Ação [Internet]. 2015 [citado em 2018 nov 21];40(2):391-405. doi: https://dx.doi. org/10.5216/ia.40i2.28762

8. Arco AR. Tecnologias da informação e da comunicação na educação em saúde. O caso da formação em enfermagem. Relatec [Internet]. 2009 [citado em 2018 nov 21];8(1):105-25. Disponível em: https:// relatec.unex.es/article/view/467/387

9. Santos GL. Ensinar e aprender no meio virtual: rompendo paradigmas. Educ Pesqui [Internet]. 2011 [citado em 2018 nov 21];37(2):307-20. Disponível em: http://revistas.usp.br/ep/article/ view/28286/30133.

10. Silva ISA, Marques IR. Conhecimento e barreiras na utilização dos recursos da tecnologia da informação e comunicação por docentes de enfermagem. J Health Inform [Internet]. 2011 [citado em 2018 nov 21];3(1):3-8. Disponível em: http://www.jhi-sbis.saude.ws/ojs-jhi/index.php/jhi-sbis/article/view/127/42

11. Francisco CCB. Formação docente: o uso de conteúdos midiáticos e das tic no processo de ensino e de aprendizagem no ensino superior. Acta Scientiarum Education [Internet]. 2011 [citado em 2018 nov 21];33(1):49-55. doi: https://dx.doi.org/10.4025/actascieduc.v33i1.11307

12. Soares-Leite WS, Nascimento-Ribeiro CA. A inclusão das TICs na educação brasileira: problemas e desafios. Magis, Revista Internacional de Investigación en Educación [Internet]. 2012 [citado em 2018 nov 21]; 5(10):173-87. Disponível em: http://www.redalyc.org/articulo.oa?id=281024896010

13. Peres $\mathrm{CM}$ et al. Aprendizado eletrônico na formação multiprofissional em saúde: avaliação inicial. Rev bras educ med [Internet]. 2012 [citado em 2018 nov 21];36(1 supl 1):134-41. Disponível em: http:// dx.doi.org/10.1590/S0100-55022012000200018

14. Quiroz JES. Estándares TIC para la formación inicial docente: una política pública en el contexto chileno. Archivos analíticos de políticas educativas [Internet]. 2012 [citado en 2018 nov 21];20(7):1-40. doi: http://dx.doi.org/10.14507/epaa.v20n7.2012

15. Goudouris ES, Giannella TR, Strichiner M. Tecnologias de informação e comunicação e ensino semipresencial na educação médica. Rev bras educ med [Internet]. 2013;37(3):396-407. doi: http:// dx.doi.org/10.1590/S0100-55022013000300012

16. Leite KNS. A utilização das tecnologias da informação e comunicação pelos docentes de enfermagem e as dificuldades no processo de ensino-aprendizagem [dissertação] [Internet]. 2014 [citado em 2018 nov 21]. Disponível em: http://tede.biblioteca.ufpb.br:8080/handle/tede/5151.

17. Rodrigues SC, Morales LS. A lousa digital na ação docente. Prisma.com [Internet]. 2015 [citado em 2018 nov 21];(28):133-44. Disponível em: http://ojs.letras.up.pt/index.php/prismacom/article/ viewFile/1847/1680

18. Muñoz Vargas IC, Rodríguez Pichardo CM, Monroy Íñiguez FJ. Desarrollo de competencias integrales con tecnologías de la información y de la comunicación en educación superior a distancia. Panorama [Internet]. 2015 [citado en 2018 nov 21]; 9(16):9-19. Disponível em: https://journal.poligran.edu.co/ index.php/panorama/article/download/631/540

19. Bueno DA. Comunicação, mídia e cidadania na prática pedagógica. Inter-Ação [Internet]. 2015 [citado em 2018 nov 21];40(3):591-606. doi: http://dx.doi.org/10.5216/ia.v40i3.28649.

20. Santos A. Tecnologias de informação e comunicação: limites e possibilidades no ensino superior. Rebes [Internet]. 2015 [citado em 2018 nov 21];1(1):36-46. doi: https://doi.org/10.18256/2447-3944/rebes. v1n1p36-46

21. Tinjacá JAW, García LLA, Sierra HFG. De los viejos individualismos a las nuevas sociedades: tecnologías de la información en la cualificación de prácticas docentes universitárias. Rev Lassalista de investigacíon [Internet]. 2016 [citado en 2018 nov 21];13(1):105-15. Disponível em: http://repository.lasallista.edu. co:8080/ojs/index.php/rldi/article/view/987/697 
22. Leite KNS, Santos SR, Andrade SSC, Zaccara AAL, Brito KKG, Sila SCR. Uso da tecnologia da informação e comunicação entre docentes à luz da teoria fundamentada nos dados. Rev enferm UFPE [Internet].2016 [citado em 2018 nov 21];10(2):515-23. Disponível em: https://periodicos.ufpe.br/ revistas/revistaenfermagem/article/download/10984/12329

23. Beltrán NMR, Gómez MEP, Lao JMI, Martinez DGP. Clínica virtual docente: un espacio formativo para la enseñanza de las ciencias médicas. Medisan [Internet]. 2017 [citado en 2018 nov 21];21(1):125. Disponível em: https://scielo.sld.cu/scielo.php?script=sci arttext\&pid=S1029

24. Cerutti E, Nogaro A. Desafios docentes no ensino superior: entre a intencionalidade pedagógica e a inserção da tecnologia. Rev Ibero-Am Estud Educ [Internet]. 2017 [citado em 2018 nov 21];12(3):1592609. doi: https://doi.org/10.21723/riaee.v12.n.3.2017.9119

25. Cunha NC, Cunha TNB, Costa SRP, Cunha NB. Gestão do conhecimento nas relações da sociedade da informação pela web. Rev SUSTINERE [Internet]. 2017 [citado em 2018 nov 21];5(1):114-34. Disponível em: https://www.e-publicacoes.uerj.br/index.php/sustinere/article/view/26707/21154

26. Heredia JM, Morales M, Vieira EMF. Uso de tecnologias digitais de informação e comunicação por docentes. Rev Conexão UEPG Ponta Grossa [Internet]. 2017 [citado em 2018 nov 21];13(1):130-41. Disponível em: http://www.revistas2.uepg.br/index.php/conexao/article/view/9391/5505 